\title{
Reintroduction of elective paediatric otolaryngology procedures in South Africa during the COVID-19 pandemic
}

\author{
J K McGuire, ${ }^{1,2}$ MB BCh, FCORL (SA), MMed (Otol); J J Fagan, ${ }^{1}$ MB ChB, FCS (SA), MMed (Otol); \\ S Peer ${ }^{1,2}$ MB BCh, FCORL (SA), MMed (Otol) \\ ${ }^{1}$ Division of Otolaryngology, Faculty of Health Sciences, University of Cape Town, South Africa \\ ${ }^{2}$ Division of Otolaryngology, Red Cross War Memorial Children's Hospital, Cape Town, South Africa
}

Corresponding author: J K McGuire (jessica.mcguire@uct.ac.za)

\begin{abstract}
Cancelling elective clinical consultations and surgical procedures was instrumental in assisting hospitals prepare for the COVID-19 crisis. Essential bed space was made available, and it allowed mobilisation of health workers and enforced social distancing. A shift in patientcentred ethics to public health ethics was required to provide a utilitarian approach to the crisis. However, at some point, clinicians need to start becoming patient centred again, and this needs to happen within the utilitarian framework. Children only account for $1-5 \%$ of confirmed COVID-19 cases, and they present with a much milder disease spectrum than adults. Consequently, paediatric units may be at the forefront of implementing reintroduction of patient-centred elective clinical and surgical procedures. The following recommendations provide a framework to do this in a way that minimises risk to patients and clinicians. They are the first paediatric guidelines in the literature to propose a strategy to reintroduce elective surgical procedures.
\end{abstract}

S Afr Med J 2020;110(7):601-604. https://doi.org/10.7196/SAMJ.2020.v110i7.14859

The World Health Organization classified the novel coronavirus disease 2019 (COVID-19) outbreak as an international emergency by declaring it a global pandemic on 11 March 2020. ${ }^{[1]}$ Although understanding of the transmission risk is incomplete, personto-person spread is primarily through droplet transmission and may occur through contact with symptomatic, presymptomatic or asymptomatic individuals. ${ }^{[2]}$ Health workers represent $4-20 \%$ of the infected population, and a large proportion of health workers develop severe symptoms. ${ }^{[3-5]}$ Procedures that have the potential to aerosolise droplets are particularly high risk, and many guidelines have recommended only performing life-saving and emergency interventions, with immediate cancellation of elective surgery. ${ }^{[6-11]}$

Risk stratification of emergency and urgent cases has meant that life-saving airway surgery and surgery for sepsis and trauma have been maintained during the outbreak and have been stratified according to time sensitivity, performed within $12-48$ hours. ${ }^{[8,10,11]}$ Urgent elective surgery such as oncological surgery has also been accounted for ${ }^{[8,10,11]}$ However, to prevent progression of complications due to delay in definitive treatment, clinicians need to start thinking about the necessity of reintroducing essential elective surgical cases. These are cases that have been delayed for $1-3$ months and in paediatric otolaryngology include adenotonsillectomies for moderate obstructive sleep apnoea, mastoidectomies for locally advancing cholesteatoma, and microlaryngoscopies for airway diseases such as laryngeal papillomatosis. ${ }^{[8,10,11]}$ Other cases would be ventilation tubes for hearing loss in children with speech delay or 'at-risk' children, and children with bilateral chronic suppurative otitis media with at least bilateral moderate hearing loss.

The paradigm behind cancelling elective surgery was four-fold. Firstly, hospitals were required to free up beds for the influx of COVID-19 cases $^{\left[{ }^{[12]}\right.}$ Secondly, from a public health perspective, social distancing (in this case preventing patients from leaving their homes and contracting the virus from high-risk facilities like hospitals) was essential to 'flatten the curve' and support health system infrastructure. ${ }^{[12]}$ Thirdly, protection of health workers was required to allow them to function within the rapidly draining services, and this included preventing them from unnecessary (particularly highrisk) exposure. ${ }^{[2-11]}$ Lastly, there is evidence to show that patients who undergo elective surgery while in the incubation period for COVID19 have poorer outcomes (surgical and COVID). In a retrospective study from Wuhan, where the outbreak began, $44 \%$ of adult patients who underwent elective surgery during their incubation period required intensive care admission, and the mortality rate was $20 \% .{ }^{[13]}$

A shift in patient-centred ethics to public health ethics has been necessary to provide a utilitarian approach to this crisis. ${ }^{[14]}$ However, as clinicians we need to start becoming patient centred again at some point, and this needs to happen within the utilitarian framework. ${ }^{[14]}$

Children only account for 1 - 5\% of confirmed COVID-19 cases, and they present with a much milder disease spectrum than adults. ${ }^{[15]}$ Paediatric units, and especially dedicated paediatric hospitals, may therefore find themselves at the forefront of implementing reintroduction of patient-centred elective surgery. This should be done in a way that does not place patients or clinicians at risk.

\section{Objectives}

To provide a systematic review on how countries that have already reached their peak in transmission rates have reintroduced elective clinical services, particularly looking at paediatric otolaryngology practice. However, there are no articles to date on an evidencebased strategy to reintroduce elective clinical procedures and elective surgery in otolaryngology, head and neck, or paediatric otolaryngology patients. 


\section{Research and methods}

A systematic review was performed in accordance with PRISMA guidelines. ${ }^{[16]}$ This review involved a systematic search of the electronic databases MEDLINE/PubMed, Google Scholar, Ovid MEDLINE and Embase. No language restrictions were applied to the search strategy. Search terms (medical subject headings or keywords) were 'SARS CoV-2', 'COVID-19', 'guidelines/practice guidelines/ clinical guidelines', 'consensus', 'ENT', 'paediatric ENT', 'pediatric ENT,' 'paediatric otolaryngology', 'pediatric otolaryngology', 'head \& neck surgery' and 'elective surgery'.

The only set of guidelines (as of 19 April 2020) on local resumption of elective surgery was from the American College of Surgeons. ${ }^{[17]}$ Using these guidelines and augmenting them with resources drawn from this pandemic, previous epidemics, and management of resource constraints in low- to middle-income countries, this article ${ }^{[17]}$ provides an evidence-based approach to safely reimplementing elective clinical and surgical procedures.

\section{Discussion}

\section{COVID-19 awareness}

\section{Community prevalence and incidence rates}

The maximum incubation period for COVID-19 is estimated to be 14 days, and the 75 th percentile is 7 days. $^{[17]}$ It is therefore recommended that a decrease in COVID-19 incidence be recognised for at least 14 days before embarking on reintroducing elective clinical and surgical procedures. ${ }^{[17]}$

\section{Screening}

Children most commonly present with features of acute respiratory infections, including fever, cough, sore throat, myalgia and fatigue. ${ }^{[15]}$ Telephonic screening, inquiring whether there has been a COVID-19 contact in the past 14 days and/or symptoms such as fever, cough or sore throat, should be performed ${ }^{[18]}$ If there is a positive COVID-19 contact or any of the screening symptoms are positive, surgery should be postponed for 2 weeks. Children should have their temperature measured on admission to hospital and the procedure should be postponed if their temperature is $>37.5^{\circ} \mathrm{C}$. The fever associated with COVID-19 in children is $>38^{\circ} \mathrm{C}$ in a third of children, but is usually $<39^{\circ} \mathrm{C}^{[15]}$ Pyrexial children should undergo diagnostic testing for COVID-19.

\section{Diagnostic testing}

Currently the National Health Laboratory Service is using molecular tests based on polymerase chain reaction methodology to detect the virus. ${ }^{[19]}$ The turnaround time is $24-48$ hours. ${ }^{[19]}$ The GeneXpert test (Cepheid), which should be introduced shortly, is a molecular test that has a faster processing time. ${ }^{[19]}$ Although it is referred to as a point-of-care test, it still requires laboratory machinery and is not a bedside test. ${ }^{[19]}$ The hope is that it will increase laboratory testing capacity and expedite results for children in whom surgery is necessary. Because false-negative results have been reported to be as high as $30 \%,{ }^{[17]}$ in patients in whom the index of suspicion is high, it would be reasonable to retest or postpone surgery for at least 2 weeks for clarification of the diagnosis.

A particular concern regarding health worker safety is the transmission potential in asymptomatic individuals or individuals who have recently recovered from the illness. Viral RNA remains in stool for $>30$ days after respiratory samples are negative. ${ }^{[17]}$ The clinical significance of this finding is not understood, but attention should be paid to meticulous hygiene practices.

\section{Governance committee}

A multidisciplinary governance committee should be assigned to oversee the reintroduction of elective clinical and surgical procedures. ${ }^{[17]}$ The members of this committee will vary depending on the hospital's requirements, but generally in South Africa (SA) should consist of members of hospital management, clinicians (surgeons and anaesthesia team), nurses, and members of the procurement department and the central sterile services department (CSSD). Nursing shortages are a notorious problem in our region. Procurement of essential equipment for surgery needs to be ensured prior to implementation of services. CSSDs may have additional responsibilities during the outbreak, and their capacity should be assessed prior to implementing services.

Service delivery in SA was a major concern in the public health sector prior to the COVID-19 crisis. This situation will be compounded once services are reinstated, and it is going to be extremely challenging to address. Clinicians and hospital management need to risk-stratify patients booked into clinics. Clinical priorities need to be carefully devised and adhered to in order to slowly relieve the patient and community backlog without overwhelming the system, while minimising complications related to delays.

\section{Reintroduction of elective surgical procedures Prioritisation}

Prioritising surgery should be sensitive to the institution's capacity and resources, as well as patients' needs. ${ }^{[17]}$ The process is a collaborative one that requires input from all the surgical disciplines, anaesthesia and nursing. ${ }^{[17]}$ An adaptable approach is advisable, as there are likely to be surges in community transmission and staff shortages due to illness. ${ }^{[17]}$

An objective scoring system like the medically necessary timesensitive (MeNTS) scoring system (Fig. 1) is ideal because it helps prioritise patients objectively and may facilitate interdepartmental agreement. ${ }^{[20]}$ The MeNTS scoring system does not take into account obstructive sleep apnoea syndrome (OSAS) in children. It may be appropriate to use the MeNTS score of '4' in children with moderate OSAS (confirmed by an OSAS grading measure of disease severity: McGill oximetry score 2). ${ }^{[21]}$ However, bear in mind that the surgery will alleviate the OSAS in these particular children.

\section{Protocol}

Preoperative considerations. A sustained decrease in the incidence of COVID-19 cases for 14 days coincides with a public health policy to slowly re-open the 'lockdown' response. ${ }^{[22]}$ Maintaining social distancing; material face masks for all; and meticulous hygiene practices in the waiting room, during consultations, on the ward and in the theatre complex are essential. ${ }^{[22]}$ Children should be entitled to have a single caregiver stay with them in the hospital, but cancellation of visiting hours should be sustained. ${ }^{[22]}$ Regular temperature checks in the paediatric ward should already be routine practice.

Routine temperature checks and COVID-19 screening should also be performed on staff members in the facility (including clinicians, nursing staff, and housekeeping, delivery and cleaning staff). ${ }^{[17]}$

Intraoperative considerations. Regular review of current COVID-19 guidelines for risk and screening is necessary. Ensure that appropriate personal protective equipment (PPE) is being used and that PPE guidelines are being followed. ${ }^{[17]}$ Buddy systems of pairing up with PPE have been shown to be effective. ${ }^{[7]}$

Postoperative considerations. Adhere to standardised care protocols. This is particularly important because staffing personnel may vary depending on shortages due to illness. ${ }^{[17]}$ 


\begin{tabular}{|c|c|c|c|c|c|}
\hline PROCEDURE & 1 & 2 & 3 & 4 & 5 \\
\hline OR time (minutes) & $<30$ & $30-60$ & $60-120$ & $120-180$ & $>180$ \\
\hline Estimated length of stay & Outpatient & $23 \mathrm{~h}$ & $24-48 h$ & $\leq 3 \mathrm{~d}$ & $>4 d$ \\
\hline Postop. ICU need, \% & Unlikely & $<5$ & $5-10$ & $10-25$ & $\geq 25$ \\
\hline Anticipated blood loss (mL) & $<100$ & $100-250$ & $250-500$ & $500-750$ & $\geq 750$ \\
\hline Surgical team size & 1 & 2 & 3 & 4 & $>4$ \\
\hline Intubation probability, \% & $\leq 1$ & $1-5$ & $5-10$ & $10-25$ & $\geq 25$ \\
\hline Surgical site & $\begin{array}{l}\text { None of the } \\
\text { following }\end{array}$ & Abdominopelvic & $\begin{array}{l}\text { Abdominopelvic } \\
\text { open surgery, } \\
\text { infraumbilical }\end{array}$ & $\begin{array}{l}\text { Abdominopelvic } \\
\text { open surgery, } \\
\text { supraumbilical }\end{array}$ & $\begin{array}{l}\text { OHNS/upper Gl/ } \\
\text { thoracic }\end{array}$ \\
\hline \multicolumn{6}{|l|}{ PROCEDURE SCORE (7 - 35) } \\
\hline DISEASE & 1 & 2 & 3 & 4 & 5 \\
\hline $\begin{array}{l}\text { Non-operative treatment } \\
\text { option EFFECTIVENESS }\end{array}$ & None available & $\begin{array}{l}\text { Available, }<40 \% \\
\text { effective as surgery }\end{array}$ & $\begin{array}{l}\text { Available, } 40-60 \% \\
\text { effective as surgery }\end{array}$ & $\begin{array}{l}\text { Available, } 60 \text { - } 95 \% \\
\text { effective as surgery }\end{array}$ & $\begin{array}{l}\text { Available, equally } \\
\text { effective }\end{array}$ \\
\hline $\begin{array}{l}\text { Non-operative treatment } \\
\text { option RESOURCE USE/ } \\
\text { EXPOSURE RISK }\end{array}$ & $\begin{array}{l}\text { Significantly worse/ } \\
\text { not applicable }\end{array}$ & Somewhat worse & Equivalent & Somewhat better & Significantly better \\
\hline $\begin{array}{l}\text { Impact of 2-week delay in } \\
\text { disease outcome }\end{array}$ & Significantly worse & Worse & Moderately worse & Slightly worse & Minimally worse \\
\hline $\begin{array}{l}\text { Impact of 2-week delay in } \\
\text { surgical difficulty/risk }\end{array}$ & Significantly worse & Worse & Moderately worse & Slightly worse & Minimally worse \\
\hline $\begin{array}{l}\text { Impact of 6-week delay in } \\
\text { disease outcome }\end{array}$ & Significantly worse & Worse & Moderately worse & Slightly worse & Minimally worse \\
\hline $\begin{array}{l}\text { Impact of 6-week delay in } \\
\text { surgical difficulty/risk }\end{array}$ & Significantly worse & Worse & Moderately worse & Slightly worse & Minimally worse \\
\hline \multicolumn{6}{|l|}{ DISEASE SCORE (6 - 30) } \\
\hline PATIENT & 1 & 2 & 3 & 4 & 5 \\
\hline Age (years) & $<20$ & $20-40$ & $40-50$ & $50-65$ & $>65$ \\
\hline $\begin{array}{l}\text { Lung disease (asthma, COPD, } \\
\text { cystic fibrosis) }\end{array}$ & None & & & $\begin{array}{l}\text { Minimal (rare } \\
\text { inhaler) }\end{array}$ & $>$ Minimal \\
\hline Obstructive sleep apnoea & Not present & & & $\begin{array}{l}\text { Mild/moderate (no } \\
\text { CPAP) }\end{array}$ & On CPAP \\
\hline $\begin{array}{l}\text { Cardiovascular disease (HTN, } \\
\text { CHF, CAD) }\end{array}$ & None & $\begin{array}{l}\text { Minimal (no } \\
\text { medication) }\end{array}$ & $\begin{array}{l}\text { Mild ( } \leq 1 \\
\text { medication) }\end{array}$ & \begin{tabular}{|l|} 
Moderate $(2$ \\
medications)
\end{tabular} & $\begin{array}{l}\text { Severe }(\geq 3 \\
\text { medications) }\end{array}$ \\
\hline Diabetes & None & & $\begin{array}{l}\text { Mild (no } \\
\text { medication) }\end{array}$ & $\begin{array}{l}\text { Moderate (oral } \\
\text { medication) }\end{array}$ & $\begin{array}{l}\text { >Moderate } \\
\text { (insulin) }\end{array}$ \\
\hline Immunocompromised* & No & & & Moderate & Severe \\
\hline $\begin{array}{l}\text { ILI symptoms (fever, cough, } \\
\text { sore throat, body aches, } \\
\text { diarrhoea) }\end{array}$ & None & & & & Yes \\
\hline $\begin{array}{l}\text { Exposure to known COVID-19- } \\
\text { positive person in past } 14 \text { days }\end{array}$ & No & Probably not & Possibly & Probably & Yes \\
\hline \multicolumn{6}{|l|}{ PATIENT SCORE $(8-40)$} \\
\hline
\end{tabular}

Fig. 1. MeNTS surgical procedure prioritisation worksheet. ${ }^{[20]}$ (MeNTS = medically necessary time sensitive; OR = operating room; ICU = intensive care unit; OHNS = otolaryngology, head and neck surgery; GI = gastrointestinal; $C O P D=$ chronic obstructive pulmonary disease; $C P A P=$ continuous positive airway pressure; $H T N=$ hypertension; $C H F=$ congestive heart failure; $C A D=$ coronary artery disease; $I L I=$ influenza-like illness; IVIG = intravenous immunoglobulin; ${ }^{*}$ Haematological malignancy, stem cell transplant, solid-organ transplant, active/recent cytotoxic chemotherapy, anti-TNFa or other immunosuppressants, $>20 \mathrm{mg}$ prednisone equivalent/d, congenital immunodeficiency, hypogammaglobulinaemia on IVIG, HIV with CD4 count $<200$ cells/ $\mu \mathrm{L}$.)

\section{Managing limited resources}

\section{Personal protective equipment}

Adequate PPE is necessary, especially if the surgical caseload is expected to increase. ${ }^{[17]}$ It is recommended that the hospital have sufficient PPE for both aerosol and droplet precautions for at least
30 days of surgery before elective surgery is implemented. ${ }^{[17]}$ The Centers for Disease Control and Prevention has a PPE calculator to help hospitals determine their PPE requirements. ${ }^{[23]}$

PPE guidelines should include recommendations for COVID19-positive patients, patients under investigation and COVID-19- 
negative patients. ${ }^{[17]}$ PPE guidelines may need to be regionally specific owing to availability of resources and innovation to circumvent these challenges. In Africa, a recommended PPE guideline is the PENTAFRICA COVID Guidelines for the Paediatric ENT Surgeon. ${ }^{[8]}$

\section{Resources and supplies}

The hospital should have appropriate levels of surgical consumable supplies before elective surgery commences. ${ }^{[17]}$ The usual supply chain should be functional, and sufficient cleaning supplies should be available. ${ }^{[17]}$

\section{Conclusions}

Once the incidence of new COVID-19 cases has decreased for 14 days, we recommend reintroduction of elective paediatric otolaryngology procedures, adhering to the above measures and commencing with adenotonsillectomies for moderate OSAS; microlaryngoscopy for airway disease; tympanomastoid surgery for selected patients with locally advanced cholesteatoma; ventilation tubes for hearing loss in children with speech delay or 'at risk' children; and tympanoplasties for children with chronic suppurative otitis media with at least bilateral moderate hearing loss. It is then possible to proceed to expanding surgical procedures to include more comprehensive elective surgery.

\section{Declaration. None.}

Acknowledgements. None.

Author contributions. JKM: study design, research and write-up; JJF: writeup and advice; SP: conceptualisation of study, study design and write-up. Funding. None.

\section{Conflicts of interest. None.}

1. World Health Organization. Coronavirus disease (COVID-19) outbreak: WHO announced COVID-19 outbreak a pandemic. http://www.euro.who.int/en/health-topics/health-emergencies/ coronavirus-covid-19/news/news/2020/3/who-announces-covid-19-outbreak-a-pandemic (accessed 19 April 2020).

2. World Health Organization. Coronavirus disease 2019 (COVID-19): Situation report - 73. https:// www.who.int/docs/default-source/coronaviruse/situation-reports/20200402-sitrep-73-covid-19. pdf?sfvrsn=5ae25bc7_2 (accessed 19 April 2020).

3. Meng L, Hua F, Bian Z. Coronavirus disease 2019 (COVID-19): Emerging and future challenges for 3. Meng L, Hua F, Bian Z. Coronavirus disease 2019 (COVID-19): Emerging and future challenges for
dental and oral medicine. J Dent Res 2020;99(5):481-497. https://doi.org/10.1177/0022034520914246
4. Wu Z, McGoogan JM. Characteristics of and important lessons from the coronavirus disease 2019 (COVID-19) outbreak in China: Summary of a report of 72314 cases from the Chinese Center for Disease Control and Prevention. JAMA 2020;323(13):1239-1242. https:// doi.org/10.1001/jama.2020.2648

5. Remuzzi A, Remuzzi G. COVID-19 and Italy: What next? Lancet 2020;395(10231):1225-1228. https:// 5. Remuzzi A, Remuzzi G. COVID-19 and
doi.org/10.1016/S0140-6736(20)30627-9

6. Kowalski LP, Sanabria A, Ridge JA, et al. COVID-19 pandemic: Effects and evidence-based recommendations for otolaryngology and head and neck surgery practice. Head Neck 2020 (epub 9 April). https://doi.org/10.1002/hed.26164

7. Open Access Atlas of Otolaryngology, Head \& Neck Operative Surgery. COVID-19 ENT/Otolaryngology Guidelines. https://drive.google.com/file/d/1GePsk5iaaub-IBdPCPcqpKNyeAQ0Ub1x/view (accessed 19 April 2020).

8. Open Access Atlas of Otolaryngology, Head \& Neck Operative Surgery. PENTAFRICA Paediatric COVID Guidelines for the Paediatric ENT Surgeon. https://bit.ly/PENTAFRICA_COVID-19 (accessed 19 April 2020).

9. American Academy of Otolaryngology-Head and Neck Surgery. Otolaryngologists and the COVID-19 pandemic. Adopted 23 March 2020. https://www.entnet.org/content/otolaryngologists-and-covid-19pandemic (accessed 19 April 2020).

10. ENT UK. Clinical guide to surgical prioritisation during the coronavirus pandemic (ENT specific). https://www.entuk.org/clinical-guide-surgical-prioritisation-during-coronavirus-pandemic-ent-specific (accessed 19 April 2020).
.

1. American College of Surgeons. COVID-19 Guidelines for Triage of Otolaryngology Patients. 24 March 2020. https://www.facs.org/covid-19/clinical-guidance/elective-case/otolaryngology (accessed 19 April 2020).

12. Ross SW, Lauer CW, Miles WS, et al. Maximizing the calm before the storm: Tiered surgical response plan for novel coronavirus (COVID-19). J Am Coll Surg 2020 (in press). https://doi.org/10.1016/j. jamcollsurg.2020.03.019

13. Lei S, Jiang F, Su W, et al. Clinical characteristics and outcomes of patients undergoing surgeries during the incubation period of COVID-19 infection. EClinicalMedicine 2020 (epub 5 April 2020). https://doi. org/10.1016/j.eclinm.2020.100331

14. Angelos P. Surgeons, ethics, and COVID-19: Early lessons learned. J Am Coll Surg 2020 (in press). https://doi.org/10.1016/j.jamcollsurg. 2020.03.028

15. Ludvigsson JF. Systematic review of COVID-19 in children shows milder cases and a better prognosis than adults. Acta Paediatr 2020;109(6):1088-1095. https://doi.org/10.1111/apa.15270

16. Moher D, Liberati A, Tetzlaff J, Altman DG; Prisma Group. Preferred reporting items for systematic Moher D, Liberati A, Tetzlaff J, Altman DG; Prisma Group. Preferred reporting items for systematic
reviews and meta-analyses: The PRISMA statement. PLoS Med 2009;6(7):e1000097. https://doi, reviews and meta-analyses: The
org/10.1371/journal.pmed.1000097

17. American College of Surgeons. COVID-19 and surgery: Local resumption of elective surgery guidance. https://www.facs.org/covid-19/clinical-guidance/resuming-elective-surgery (accessed 19 April 2020).

8. National Department of Health, South Africa. COVID-19 screening campaign. http://www.health.gov. za/index.php/gf-tb-program/477-covid-19-screening (accessed 17 May 2020).

19. National Institute for Communicable Diseases: Division of the National Health Laboratory Services. COVID-19 update. https://www.nicd.ac.za/covid-19-update-26/ (accessed 21 April 2020).

20. Prachand VN, Milner R, Angelos P, et al. Medically-necessary, time-sensitive procedures: A scoring system to ethically and efficiently manage resource scarcity and provider risk during the COVID-19 pandemic. J Am Coll Surg 2020 (in press). https://doi.org/10.1016/j.jamcollsurg.2020.04.011

21. Nixon GM, Kermack AS, Davis GM, Manoukian JJ, Brown KA, Brouillette RT. Planning adenotonsillectomy in children with obstructive sleep apnea: The role of overnight oximetry. Pediatrics 2004;113(1):e19-e25. https://doi.org/10.1542/peds.113.1.e19

22. American Enterprise Institute. National coronavirus response: A road map to reopening. https://www. aei.org/research-products/report/national-coronavirus-response-a-road-map-to-reopening/ (accessed 21 April 2020).

23. Centers for Disease Control and Prevention. Ebola PPE calculator. https://www.cdc.gov/vhf/ebola/ healthcare-us/ppe/calculator.html (accessed 21 April 2020).

Accepted 6 May 2020 